\title{
METACOGNIÇÃO E APRENDIZAGEM AUTORREGULADA NA FORMAÇÃO PROFISSIONAL
}

\author{
Adriana Croti, Carmen Lúcia Dias, Adriano Rodrigues Ruiz \\ Universidade do Oeste Paulista - UNOESTE. Mestrado em Educação, Presidente Prudente - SP. E-mail: \\ adrianacroti@hotmail.com
}

\section{RESUMO}

A Revolução digital promoveu mudanças nas exigências de competências cognitivas para o trabalho em todo o mundo, inclusive no Brasil. Diante da "bolha do emprego" que surgiu no inicio século XXI o olhar politico voltou-se para o ensino médio profissionalizante com vistas à capacitação profissional, principalmente do publico jovem. A instituição dos programas Jovem Aprendiz e PRONATEC auxiliaram na mudança de cenário da educação profissionalizante no Brasil. A partir da leitura de pesquisadores sobre a temática, este artigo aborda aspectos sobre metacognição e aprendizagem autorregulada. A importância do aprender a aprender para o desenvolvimento de atitudes ativas autorreguladas de aprendizagem, que implicam em aspectos procedimentais da consciência, vai além do desenvolvimento de meras competências, ele desenvolve um sujeito independente e responsável para alcançar uma carreira profissional de contínuo aprendizado.

Palavras-chave: Aprendizagem. Aprendizagem autorregulada. Mercado de trabalho e metacognição.

\section{METACOGNITION AND SELF-REGULATED LEARNING IN PROFESSIONAL EDUCATION}

\begin{abstract}
The digital Revolution promoted changes in the exigencies of cognitive competences for the work around the world, included in Brazil. In face of the "job bubble" that appeared in the beginning of $21^{\text {st }}$ century the political look turned to the technical high school aiming the professional qualification, mainly of the young public. The establishment of the Young Apprentice Programs and PRONATEC assisted in the scenery change of the Brazil professional education. From reading of researchers about this thematic, this article addresses aspects about the metacognition and self-regulated learning. The importance of lear to learn to develop active attitudes self-regulated learning, wich imply procedural aspects of consciousness goes beyond the mere development of skills, he develops a subject independent and responsible for achieving a career of continuous learning.
\end{abstract}

Keywords: Learning, Self-regulated learning, job market and metacognition. 


\section{INTRODUÇÃO}

Desde a Revolução digital, as alterações na economia mundial tem afetado o modo de relação empregado versus empregador. O formato das relações comerciais no sistema globalizado, associado às questões de ordem econômica mundial, promoveu a busca pela qualidade e produtividade que, inevitavelmente, afetaram trabalhadores em todo mundo, inclusive no Brasil.

Se, por um lado, as demandas econômicas requerem das empresas qualidade e produtividade de forma emergencial, por outro, o aprendizado demanda tempo. Daí surgem reflexos como a "bolha do emprego" (sobra de vagas de emprego e falta de mão de obra qualificada), como a que acontece neste inicio de século XXI.

A economia para continuar se desenvolvendo de forma sustentável deve contar com a melhoria na qualidade dos recursos humanos (SCHWARTZMAN; CASTRO, 2013).

Diante desta posição é necessário observar alguns fatos referentes ao ensino profissionalizante. A década de 1990 forneceu elementos contextuais à compreensão destas discussões, principalmente nos aspectos de acesso, permanência, democratização e universalização à educação profissional no Brasil; em especial as políticas educacionais por meio da Conferência Mundial de Educação para Todos (SCHWARTZMAN; CASTRO, 2013).

É nesta década que o olhar político voltou-se para a regulamentação da capacitação de profissionais, principalmente o público jovem, com enfoque para as áreas de ensino médio profissionalizante. Para atender esta demanda instituiu-se a Lei de Aprendizagem 10.097/2000 (BRASIL, 2000) que, entre outros objetivos oportuniza aos jovens entre 14 e 24 anos obter o primeiro emprego; pelo programa Aprendiz Legal. E mais recentemente o lançamento do Programa Nacional de Acesso ao Ensino Técnico e Emprego - PRONATEC, instituído por lei federal - 12.513/2011 (BRASIL, 2011).

À vista destas mudanças iniciadas na década de 1990 e, face aos processos produtivos cada vez mais informatizados, além das alterações nas relações pessoais de trabalho, houve a necessidade de retomar a valorização da educação formal e da capacitação profissionalizante como forma de garantir um melhor nível de vida aos ingressantes no mercado de trabalho (MUSSE; MACHADO, 2013). A educação técnica torna-se, então, responsável por desenvolver nos jovens as faculdades técnicas necessárias ao processo produtivo, bem como as relações sociais que regulam os ambientes de trabalho (SCHWARTZMAN; CASTRO, 2013).

Contudo, é importante salientar que estes jovens são estudantes de escolas públicas, e apresentam dificuldades de aprendizagem como as apontadas pelo relatório "De olho nas Metas", que segundo a análise dos dados do Sistema de Avaliação da Educação Básica Brasileira, SAEB - em 
2011, indica que apenas 11\% dos jovens cursando a terceira série do Ensino Médio dominavam os conhecimentos mínimos de matemática, e apenas $28.9 \%$ dominavam os conhecimentos mínimos de língua portuguesa. (TODOS PELA EDUCAÇÃO, 2012, p.50).

Outro aspecto relevante a ser observado trata-se da pouca idade dos jovens. Este fato contribui para a pouca experiência no aspecto pessoal e comportamental no âmbito profissional. Por isso, além de saberes técnicos, a postura e o comportamento precisam ser moldados para este novo ambiente, é uma nova fase de vida que se inicia para eles. E como aprender, apreender e aplicar saberes diversos em pouco espaço de tempo?

\section{CRIANDO LAÇOS: CONHECIMENTO E APRENDIZAGEM}

Aprender requer um processo laborioso de construção de conhecimento, envolvendo as funções cognitiva, afetiva, psicomotora, social e cultural.

Bordenave (1995, p.25) salienta que

a aprendizagem é um processo integrado no qual toda a pessoa (intelecto, afetividade, sistema muscular) se mobiliza de maneira orgânica. Em outras palavras, a aprendizagem é um processo qualitativo, pelo qual a pessoa fica melhor preparada para novas aprendizagens. Não se trata, pois, de um aumento quantitativo de conhecimentos, mas de uma transformação estrutural da inteligência da pessoa.

Desta forma, nota-se um descompasso de tempo que provoca uma dicotomia entre o que o mercado pede e o que os jovens trabalhadores podem oferecer.

Neste aspecto para Morin (2000, p. 39) a educação deve considerar que "o conhecimento, ao buscar construir-se com referência ao contexto, ao global e ao complexo, deve mobilizar o que o conhecedor sabe do mundo."

Bruner (2001, p. 28-29) considera que

a educação deve ser concebida como algo que auxilie o ser humano a aprender a utilizar as ferramentas de produção de significado e de construção de realidade, a adaptar-se melhor ao mundo que ele se encontra, ajudando no processo de modifica-lo quando necessário. Neste sentido, ela pode até mesmo ser concebida como ajudando as pessoas a se tornarem melhores arquitetos e melhores construtores.

Assim, Freire complementa

é preciso ensinar estratégias que permitam enfrentar os imprevistos, o inesperado e a incerteza, modificando seu desenvolvimento, em virtude das informações adquiridas ao longo do tempo. Dessa forma, roga-se à escola que transforme seu papel como instituição de ensino. Sendo necessário introduzir e 
desenvolver, através de práticas educativas baseadas na compreensão, a autonomia dos alunos, apoiada num papel mais ativo dos mesmos, já que não basta mais transmitir, mas encorajá-los a serem capazes, eles próprios, de selecionarem, construírem e transferirem o conhecimento. (FREIRE, 2009, p.277)

Possuir capacidade de julgar, adquirir autoconfiança e motivação, são hoje características necessárias ao ingresso no mercado de trabalho, mas para alcançar este status é necessário estar em constante atualização. Isto implica que estes jovens devam "aprender a aprender" viver para e no mercado de trabalho.

\section{APRENDER A APRENDER}

Mas como apresentar-Ihes um mundo novo, "o mundo profissional" distante das disciplinas curriculares do ensino fundamental e médio? Esta questão conduz ao pensar de Sócrates, ao dizer só sei que nada sei e o fato de saber isso me coloca em vantagem sobre aqueles que acham alguma coisa (SILVA; PAGNI, 2007). Nestes pressupostos, o caminho me conduz à aprendizagem autorregulada e à metacognição.

Flavell, a partir dos estudos realizados na área da memória, em 1970, foi o primeiro autor a referir-se à metacognição, definindo-a como o conhecimento que o sujeito tem sobre o seu próprio conhecimento, ou seja, o conhecimento dos próprios processos e produtos cognitivos, ou algo relacionado com eles (FIGUEIRA, 2003 p.1).

No âmbito de estudo educacional duas formas de entendimento vêm sendo aplicadas à metacognição. Uma aborda o conhecimento sobre o conhecimento - tomada de consciência do seu próprio pensar, noutra o controle ou autorregulação - capacidade de avaliar e corrigir a execução da atividade cognitiva. Embora sejam enfoques distintos, encontram-se intimamente relacionados, e tentar dissociá-los provoca apenas uma simplificação sem sentido. (RIBEIRO, 2003).

Portilho (2011, p. 103) dá ênfase ao que foi colocado quando define "a metacognição como um dos caminhos do autoconhecimento no processo de aprendizagem." Sendo assim, o aluno ao se valer do autoconhecimento para definir suas estratégias de aprendizagem determina o seu caminho para a autorregulação.

Citando Bandura e Walters (1963), Portilho (2011 p. 119) destaca que

a autorregulação é um tipo de aprendizagem progressiva, onde a pessoa com o passar do tempo melhora sua capacidade de execução da atividade sem a presença de um modelo ou mediador. Trata-se de um processo lento que tem inicio externamente e posteriormente torna-se interno, onde o sujeito controla seu próprio pensamento. 
Vygotsky (2009) atribui papel preponderante às relações sociais no processo de aprendizagem, considerando que o controle cognitivo é primeiramente um processo social, isto é, adquirido por meio de uma aprendizagem mediada. Por isso, a aprendizagem mediada confere um papel de destaque ao professor. Preconiza-se que seja possibilitado ao aluno não só uma aprendizagem de conteúdos, mas de aplicabilidade dos conceitos a situações da vida real.

Desta forma, a aprendizagem inicia-se com a mediação, que com o tempo torna-se autorregulada, ou seja, passa a ser planejada, organizada e controlada ajustando-se aos diferentes sujeitos que, autônomos, avaliam e corrigem as estratégias adotadas.

Segundo Mizukami (1986, p. 64), o conhecimento humano é essencialmente ativo. A aprendizagem verdadeira se dá no exercício operacional da inteligência. Só se realiza realmente quando o aluno elabora seu conhecimento. A inteligência é o instrumento de aprendizagem mais necessário (MIZUKAMI, 1986 p.77).

Apoiando-se em Lima (1980) Mizukami (1986, p. 61 ) define inteligência como uma forma de coordenação de ação (motora, verbal, ou mental) a uma situação nova com o objetivo a) de auto organizar-se para enfrentar a situação e b) de encontrar um comportamento (invenção, descoberta) que mantenha o equilíbrio entre o organismo e o meio.

Sendo assim deve o professor criar condições que submeta os alunos a desafios, a busca por respostas, a cooperação com o intuito de que possam alcançar o quadro teórico-prático num quadro crescente de complexidade. Apenas a troca de ideias dá liberdade ao pensamento e à sua expressão, que são as condições imprescindíveis para o aperfeiçoamento do ser humano.

No tocante à educação profissionalizante é mister considerar as relações dos alunos com outros (seus pares), com o ambiente profissional e com o mundo; incluindo as relações de saberes entre as diferentes atividades executadas na organização.

Desta forma, observa-se que a relação entre aluno e professor deve ser de mútua responsabilidade na conquista do conhecimento com uma postura de colaboração e parceria. Para que assim juntos, conquistem a profunda compreensão do significado de "aprender a aprender".

A pedagogia moderna está cada vez mais em direção à visão de que o aluno deve estar ciente de seus próprios processos de pensamento e que é essencial, tanto para o pedagogo quanto ao professor, ajudá-lo a tornar-se mais metacognitivo - a estar tão ciente de como realiza sua aprendizagem e pensamento quanto da matéria que está estudando. 


\section{CONSIDERAÇÕES FINAIS}

Diante destas reflexões surgem algumas questões. Como provocar o aluno a tornar-se autorregulado? Como o aluno percebe o funcionamento da sua inteligência para aprendizagem? Como estimular o "aprender a aprender" deste aluno para que desenvolva sua carreira profissional?

Portilho (2011, p. 105) responde a tais inquietações quando afirma que "o ensino deve estimular o aluno a parar, refletir sobre sua própria maneira de ser, pensar, agir e interagir, convidando a melhorar sua aprendizagem de forma consciente"

Os aspectos procedimentais da consciência implica em que aprendamos a realizar as tarefas de sala de aula e do cotidiano.

A importância do aprender a aprender para o desenvolvimento de atitudes ativas autorreguladas de aprendizagem vai além do desenvolvimento de meras competências. Quando o sujeito aprende a aprender, ele controla o que e como aprende, torna-se mais independente e responsável. E ainda, estabelece melhor interação com o mundo e consigo mesmo e, desta forma, com o mercado de trabalho para alcançar uma carreira profissional de conquistas e contínuo aprendizado.

\section{REFERÊNCIAS}

BRASIL. Lei no 12.513, de 26 de outubro de 2011. Institui o Programa Nacional de Acesso ao Ensino Técnico e Emprego (Pronatec). Diário Oficial [da] República Federativa do

Brasil, Brasília, DF, 27 out. 2011. . Lei n-10.097, de 19 de dezembro de 2000. Altera dispositivos da Consolidação das Leis do Trabalho - CLT, regulando a contratação de Jovens Aprendizes. Diário Oficial [da] República Federativa do Brasil, Brasilia, DF, 20 dez. 2000.

BRUNER, J. A cultura da educação. Porto Alegre: Artmed Editora, 2001.

DIAZ BORDENAVE, J. E.; PEREIRA, A. M. estratégias de ensino-aprendizagem. 16 ed. Petrópolis: Vozes, 1995.

FIGUEIRA, A P C. Metacognição e seus contornos. Revista Iberoamericana de Educación, 10/6/2003; (ISS: 1681-5653). Disponível em http://www.rieoei.org/deloslectores/446Couceiro.pdf, acesso em: 12/Mai/2014.

FREIRE, L. G. L. Auto-regulação da aprendizagem. Ciências e Cognição / Science and Cognition, [S.I.], v. 14, n. 2, jun. 2009. ISSN 1806-5821. Disponível em: <http://www.cienciasecognicao.org/revista/index.php/cec/article/view/115/88 Acesso em: 12 Maio 2014. 
MIZUKAMI, M. da G. N. Ensino: as abordagens do processo. São Paulo: EPU, 1986.

MORIN, E. A cabeça bem feita: repensar a reforma, reformar o pensamento. 2. ed. Rio de Janeiro: Bertrand Brasil, 2000.

MUSSE, Isabel; MACHADO, Ana Flavia. Perfil dos indivíduos que cursam educação profissional no Brasil. Econ. soc, Campinas , v. 22, n.1, Apr. 2013. Disponível em <http://www.scielo.br/scielo.php?script=sci_arttext\&pid=S010406182013000100008\&Ing=en\&nr $\mathrm{m}=\mathrm{iso}>$. Acesso em 18 maio 2014

PORTILHO, E. como se aprende? estratégias, estilos e metacognição. 2. ed. Rio de Janeiro: Wak Ed., 2011

RIBEIRO, Célia. metacognição: um apoio ao processo de aprendizagem. Psicol. Reflex. Crit., Porto Alegre $\quad$ v. 16, n. 1, 2003. Disponível em <http://www.scielo.br/scielo.php?script=sci_arttext\&pid=S0102$79722003000100011 \&$ lng=en\&nrm=iso>. Acesso em 12/05/2014.

SILVA, D. J. da; PAGNI, P. A. A educação na filosofia de sócrates. In: Introdução à Filosofia da Educação - Temas Contemporâneos e História. São Paulo: Avercamp, 2007.

SCHWARTZMAN, S.; CASTRO, C de M. Ensino, formação profissional e a questão da mão de obra. Ensaio: avaliação e políticas públicas em educação, Rio de Janeiro, v. 21, n. 80, Sept. 2013. Disponível em

<http://www.scielo.br/scielo.php?script=sci_arttext\&pid=S010440362013000300010\&lng=en\&nr m=iso>. Acesso em 23/05/2014.

TODOS PELA EDUCAÇÃO. De Olho nas Metas 2011: Quarto Relatório de Monitoramento das 5 metas do Todos Pela Educação. São Paulo, 2012.

VYGOTSKY, L. S. A construção do pensamento e da linguagem. 2. ed. São Paulo: Martins Fontes, 2009. 